\title{
Caught in the middle in mid-life: provision of care across multiple generations
}

\author{
Athina Vlachantoni ${ }^{1,2 *}$, Maria Evandrou ${ }^{1,2}$, Jane Falkingham ${ }^{1}$ and Madelin Gomez-Leon ${ }^{3}$ \\ ${ }^{1}$ ESRC Centre for Population Change, Faculty of Social Sciences, University of Southampton, Southampton, \\ UK, ${ }^{2}$ Centre for Research on Ageing, Faculty of Social Sciences, University of Southampton, Southampton, \\ UK and ${ }^{3}$ Department of Political and Social Sciences, Pompeu Fabra University, Barcelona, Spain \\ ${ }^{*}$ Corresponding author. Email: A.Vlachantoni@soton.ac.uk
}

(Accepted 8 January 2019; first published online 8 February 2019)

\begin{abstract}
With a large baby-boomer generation entering mid-later life in the United Kingdom, and families spanning across multiple generations, understanding how individuals support multiple generations is of increasing research and policy significance. Data from the British 1958 National Child Development Study, collected when respondents were aged 55 , are used to examine how mid-life women and men allocate their time to support elderly parents/parents-in-law and their own adult children in terms of providing grandchild care, and whether there is a trade-off in caring for different generations. Binary logistic and multinomial regression models distinguish between individuals supporting multiple generations, only one generation or none. One-third of mid-life individuals are 'sandwiched' between multiple generations, by having at least one parent/parent-in-law and one grandchild alive. Among them, half are simultaneously supporting both generations. Caring for grandchildren increases the probability of also supporting one's parents/parents-in-law, and vice versa. More intense support for one generation is associated with a higher likelihood of supporting the other generation. Good health is associated with caring for multiple generations for men and women, while working part-time or not at all is associated with such care provision for women only. Facilitating mid-life men and women in responding to family support demands whilst maintaining paid employment will be critical in fostering future intergenerational support.
\end{abstract}

Keywords: care provision; sandwich generation; support; intergenerational exchange

\section{Introduction}

With improving life expectancy, increasing female employment and changing family formation, baby-boomers entering mid- and later life face the prospect of juggling multiple roles, combining paid work with family obligations (Evandrou and Glaser, 2004; Fingerman et al., 2012). Increasing survival into older ages allows more individuals to share their mid-life with older generations, who may be in

(C) Cambridge University Press 2019. This is an Open Access article, distributed under the terms of the CreativeCommons Attribution licence (http://creativecommons.org/licenses/by/4.0/), which permits unrestricted reuse, distribution, and reproduction in any medium, provided the original work is properly cited 
need of support (Wiemers and Bianchi, 2015), whilst postponement of childbirth and delays in transition into independence mean that more individuals in mid-life have continuing commitments to their (adult) children (Stone et al., 2014). Over the past decade, the number of people at risk of simultaneously providing care for children and parents, the so-called 'sandwich generation', has grown (Rubin and White-Means, 2009; Friedman et al., 2015).

Although the 'sandwiched generation' has been empirically studied in the United States of America (USA) (Abramson, 2015; Friedman et al., 2015) and Ireland (McGarrigle and Kenny, 2013), research in the United Kingdom (UK) remains sparse. Previous British studies have primarily relied upon data from a decade or more ago (Evandrou and Glaser, 2002; Evandrou et al., 2002; Agree et al., 2003; Glaser et al., 2006; Grundy and Henretta, 2006); since then significant socioeconomic and policy changes have taken place, altering the institutional context within which families live. Successive UK governments have reduced young adults' social security entitlements, replacing university student grants with loans, removing entitlement to social benefits such as jobseeker's allowance and income support for 16- and 17-year-olds, and most recently restricting housing benefit for single people under 35 to only cover the cost of renting in shared accommodation (Stephens and Blenkinsopp, 2015). Benefits to working families with young children have also been reduced and, although the government has recently introduced 15 hours of free child care per week for three- and four-year-olds (Department for Education, 2014), the cost of child care means that many parents (frequently mothers) are unable to work full-time without family support. Meanwhile, the provision of long-term care to older people continues to rely heavily on informal carers, most of whom are family members. Research using data from the 2011 Census of England and Wales found that the prevalence of providing care peaks around ages 45-54 for women and 45-64 for men, coinciding with the lifecourse stages currently being targeted in efforts to extend working lives (Robards et al., 2015; Department for Work and Pensions, 2017).

Against this background, this research uniquely contributes to understanding the current trends and profile of the sandwich generation in the UK, using data from the National Child Development Study. It investigates the extent to which the provision of grandchild care affects the provision of support to older generations and vice versa, and examines the determinants of caring for both generations compared with caring for one generation, or none; taking also the intensity of care provision into account. The paper uses the provision of help with grandchild care as the main indicator of help provided by the older to the younger generation; firstly, because this was the only type of help with detailed information in the specific dataset used in this study; and secondly, because the provision of grandchild care has been shown in existing literature to be one of the most important types of help provided by older parents to their adult children (Grundy and Henretta, 2006; Evandrou et al., 2018).

The research addresses the following questions:

- How do mid-life men and women distribute their care provision between their elderly parents/parents-in-law and grandchildren? 
- Does caring for one generation reduce the likelihood of caring for the other generation?

- What are the socio-demographic characteristics distinguishing those caring for multiple generations from those caring for only one generation, or for none?

The paper first outlines the profile of 'sandwiched' individuals and the prevalence and intensity of care provision towards their parents/parents-in-law and/or grandchildren. It then examines whether caring for one generation, and by how much, affects the likelihood of caring for the other generation, before identifying the socioeconomic and demographic characteristics of individuals caring for one, both or none of the generations.

\section{Existing research}

There is extensive literature on the care provided by adult children to their older parents and the impact of such provision on the carers' health and employment (Dykstra and Fokkema, 2011), and on the exchange of care between the two generations (Henretta et al., 1997; Evandrou et al., 2018). There is also significant literature on the support provided by parents to their (adult) children (Heath and Calvert, 2013) and grandchildren (Arpino and Bordone, 2017). The majority of studies since the 1980s, when the 'sandwich generation' was first studied (Miller, 1981), have focused on women's informal caring towards multiple generations, reflecting the gendered nature of caring (Dahlberg et al., 2007). Those rarer studies exploring men's care-giving have also found evidence of their involvement, but at a lower intensity than women (Friedman et al., 2015).

The definition of the 'sandwich' generation, and the age range of the target population, has shifted over time reflecting the need to accommodate the growing complexity of multigenerational relations (Abramson, 2015). Earlier studies primarily focused on how women of child-bearing age with dependent children managed care towards older parents, with Rosenthal et al. (1996) concluding that being 'caught in the middle' was far from a typical experience. As Grundy and Henretta (2006: 708) point out, experiencing simultaneous caring responsibilities for elderly parents and dependent children requires 'either later-than average childbearing in two successive generations or the unusually early onset of disability in the oldest generation'. Rogerson and Kim (2005) argued that a more appropriate designation might be the 'stretched' generation, as many members of the US baby-boom cohort were only beginning to care for ageing parents as they completed child rearing.

More recently, being 'sandwiched' between 'dependent' children and older parents has been extended to include younger adults requiring help from their parents, for instance due to illness, financial or accommodation difficulties, or a need for grandchild care (Fingerman et al., 2010; Evandrou et al., 2018). Previous studies on intergenerational support have focused on the financial and time resources dedicated by the older generation to providing grandchild care (Grundy and Henretta, 2006), emphasising the importance of such help in the relationship between adult children and their older parents.

Changes in survivorship over the past century have meant that more mid-life individuals now have parents alive for longer and four-generation families are 
more common (Murphy and Grundy, 2003). Demands from the 'downward' generation may emanate from children of any age and throughout the lifecourse, relating to co-residence with one's parents regardless of age (e.g. Wiemers and Bianchi, 2015 ) or the provision of grandchild care (e.g. Lumsdaine and Vermeer, 2015).

The extent of being sandwiched between two (or three) generations and actually providing care to such generations varies considerably, depending on the definition and target age groups. Research using the National Longitudinal Survey of Young Women found that just 9 per cent of US women aged 45-56 cared for their parent and dependent children (Pierett, 2006). However, using a broader definition (all those aged 35-75 and including children aged 18 and over), Friedman et al. (2015) showed that around 30 per cent of this group were providing time or money to both generations. A study comparing data from the USA and Great Britain from the 1980s and 1990s defined the sandwich generation as those aged 55-69 with at least one child and one parent alive, and found that 30 per cent of such individuals were helping both generations either with child care, non-financial or financial support (Grundy and Hernetta, 2006). More recently, a report using 2009-2011 data from Ireland found that 31 per cent of individuals aged between 50 and 69 were sandwiched between their parents and children, and 60 per cent of those were simultaneously providing grandchild care and non-financial help to their own parents (McGarrigle and Kenny, 2013).

One of the central issues regarding caring for multiple generations is how carers divide their resources (time, finance, etc.) between the older and younger generation. This is particularly pertinent in a context where the state is increasingly dependent on the family for the provision of social care for older people, but at a time when public funding for child care is reducing (Department for Education, 2014), and when both mid-life women and men are being encouraged to remain in the labour market for longer (Department for Work and Pensions, 2017). A key question is whether the needs of children (or grandchildren) compete with the needs for support amongst older parents, or whether they are complementary. Previous studies have provided backing for the 'solidarity hypothesis' against the 'competing demand hypothesis', with helping one generation being linked with helping another generation (Grundy and Henretta, 2006; Fingerman et al., 2010). However, the study by Grundy and Henretta (2006) also found that care towards one's parent declines when there is a higher number of members from the younger generation alive. This paper adds uniquely to the literature by examining the extent to which care provision by so-called sandwiched individuals towards one generation in the UK affects this group's chances of providing care towards the other generation, also taking into account the intensity of care provided.

\section{Design and methods}

This research employs a cohort study, the National Child Development Study (NCDS), which began with more than 17,000 children born in a single week in March 1958 in Britain, who have been followed up at regular intervals throughout their lives. The respondents were last interviewed in 2013 at age 55 (Wave 9; total sample 9,137), when information was collected both on support provision towards their parents/parents-in-law and care provided to grandchildren. 


\section{Identifying the sandwich generation}

The analytical sample comprises all individuals who were interviewed at 55, and were 'at risk' of supporting multiple generations (i.e. having at least one parent or parent-in-law alive and having at least one grandchild alive), with the provision of grandchild care being understood as the indirect provision of support by the respondent towards their own child. Excluding respondents with missing information on any of the co-variables in the multivariate analysis, the final sub-sample was 2,427 individuals (Table 1).

\section{Provision of support to parents/parents-in-law}

Each respondent was asked about their own support provision towards their parents/parents-in-law: 'Do you regularly or frequently do any of the things listed for your parents?' Response: 'Please select Yes or No for each activity listed below: dressing, eating, bathing, washing, ironing, cleaning, cooking, financial assistance, shopping, transportation, gardening and others.'

Provision of care towards parents/parents-in-laws is defined here as helping with at least one of the activities mentioned above.

The survey also collected information on how much time individuals spent completing these tasks, allowing the construction of a variable measuring the intensity of caring: 'How many hours do you spend doing this/these things for [parents or parents-in-law] in a typical week? Response: '0 ... 168.'

Responses to these questions were summed to produce a variable with four categories: not caring; nine or less hours per week; 10-19 hours per week; and 20+ hours per week. For the multivariate models, the last two categories were combined, reflecting the fact that few individuals, especially men, were caring for more than 20 hours per week (i.e. distinguishing between: not caring; nine or less hours per week; $10+$ hours per week).

\section{Provision of grandchild care}

Respondents were asked if they have any grandchildren, including stepgrandchildren and adopted grandchildren, irrespective of whether the parents of the grandchildren were alive or not. The frequency and intensity of grandchild care provided by each respondent themselves was then identified using the following questions: 'Do you ever look after any of your grandchildren, without their parents being there?' and 'How often do you look after grandchild/grandchildren, without their parents being there?' Response: 'At least once a week / At least once a month / Less often than once a month.' For both of the responses, they were also asked: 'How many hours do you spend looking after grandchild/grandchildren? (including looking after them overnight).'

For those caring at least once a month, the hours of care were adjusted to create a variable equivalent to weekly hours of support, which was re-coded into a categorical variable with the same categories as those for the intensity of parental support, i.e. not caring; nine or less hours per week; 10-19 hours per week; and 20+ hours per week. Those who looked after their grandchild less often than once a month 
Table 1. Cohort respondents at age 55 by sex and whether they have at least one parent/parent-in-law and one grandchild alive

\begin{tabular}{|c|c|c|c|c|c|c|}
\hline \multirow[b]{2}{*}{ Group } & \multicolumn{2}{|c|}{ Male } & \multicolumn{2}{|c|}{ Female } & \multicolumn{2}{|c|}{ Total } \\
\hline & $\mathrm{N}$ & $\%$ & $\mathrm{~N}$ & $\%$ & $\mathrm{~N}$ & $\%$ \\
\hline $\begin{array}{l}\text { 1. No parent/parent-in-law alive or } \\
\text { grandchildren } \text { alive }^{1}\end{array}$ & 454 & 11.1 & 589 & 13.6 & 1,043 & 12.4 \\
\hline $\begin{array}{l}\text { 2. At least one parent/parent-in-law } \\
\text { alive, no grandchildren }{ }^{2}\end{array}$ & 2,288 & 55.9 & 1,911 & 44.0 & 4,199 & 49.8 \\
\hline $\begin{array}{l}\text { 3. At least one grandchild alive, no } \\
\text { parent/parent-in-law alive }\end{array}$ & 243 & 6.0 & 516 & 11.9 & 759 & 9.0 \\
\hline $\begin{array}{l}\text { 4. At least one parent/parent-in-law } \\
\text { and grandchild alive (sandwich } \\
\text { individuals) }\end{array}$ & 1,102 & 27.0 & 1,325 & 30.5 & 2,427 & 28.8 \\
\hline Total & 4,087 & 100.0 & 4,341 & 100.0 & 8,428 & 100.0 \\
\hline $\begin{array}{l}\text { At least one parent/parent-in-law or } \\
\text { one child alive }\end{array}$ & & 52.92 & & 51.97 & & 52.43 \\
\hline
\end{tabular}

Notes: 1 . Sixty-three per cent of these individuals have at least one child alive (57.9\% for men and $66.2 \%$ for women). 2. Eighty per cent of these individuals have at least one child alive ( $80.5 \%$ for men and $79.8 \%$ for women).

Source: Authors' own analysis, National Child Development Study (Wave 9).

were classified in the low-intensity group of 'nine or less hours a week' in the absence of further information.

\section{Key explanatory variables}

Fingerman et al. (2010) highlight the importance of 'need' in determining parental support, finding that mid-life adults provided more support to parents with a disability. Unfortunately, the NCDS did not collect information on the health of the respondents' parents at Wave 9, or the need for grandchild care, thus it is not possible to control directly for the need for support from each generation. Previous studies have used the number of individuals from each generation as a proxy for the level of demand (Fingerman et al., 2010). The number of grandchildren and parents/parents-in-law alive; and information on co-residence with parents/ parents-in-law or grandchildren was therefore included to capture this, although co-residence with either of the two generations is not very prevalent in the sample, with less than 5 per cent in each of these categories. The following characteristics of the respondents were included as covariates to account for observable heterogeneity: housing tenure, education, marital status, health status, and the employment status for both the respondent and their partner.

\section{Analytical strategy}

The analysis is conducted in three stages. Firstly, the paper examines the characteristics of sandwiched individuals, before focusing on their care provision by their gender and the intensity of the support. The second stage uses logistic regression 
to investigate the association between supporting one generation and supporting the other, controlling for several demographic and socio-economic covariates. The final stage examines how the characteristics of care-givers towards multiple generations differ from the characteristics of those who care for only one generation, using multinomial logistic regression and controlling for a set of socioeconomic covariates.

The intensity of care-giving, measured in hours of care provided per week, was tested in preliminary analysis as a continuous variable, producing similar results as when using a categorical variable. However, following previous studies (Robards et al., 2015; Gomez-Leon et al., 2019), the categorical variable with the following categories was used in the final analysis: not caring, nine or less hours per week, 10-19 hours per week, 20+ hours per week for the first set of analysis; and not caring, nine or less hours per week, 10+ hours per week for the second set of analysis, which combined the last two categories previously mentioned, due to the low sample size in the $20+$ hours per week category to be included in the logistic models.

\section{Results}

Table 1 shows the prevalence of the 'sandwich generation' in the sample. Almost one-third (28.8\%) of the cohort at age 55 had both a parent/parent-in-law and a grandchild alive and thus were currently at risk of providing support towards both generations. Just under one in ten (9\%) had a grandchild but no surviving parent/parent-in-law and a further 12.4 per cent did not have relatives from either generation (parent/parent-in-law or grandchild) alive. Almost half of the respondents (49.8\%) had at least one parent/parent-in-law alive but no grandchildren; of these 80 per cent have an adult child alive, indicating that some of them might become grandparents in the future, and join the sandwich generation.

Figure 1 shows the generational structure within the family, focusing on the number of grandchildren and parents/parents-in-law alive for men and women. About two-thirds of women and nearly 70 per cent of men did not have any grandchildren at age 55, reflecting the fall in fertility over the past half century along with the rise in the average age at first birth. From vital registration data published by the UK Office for National Statistics, an estimated 18 per cent of women in England and Wales born in 1958 remained childless at age 45 and their average completed family size was 1.99; this compares with just 12 per cent childless and an average completed family size of 2.42 amongst women born in 1935, who might be considered their parental generation (Office for National Statistics, 2016). Interestingly, the mean age of mothers at first birth has risen from 24.8 years when the respondents themselves were born, to 27.0 in 1985, when they themselves might be giving birth, and has increased further to 28.3 in 2013 (Office for National Statistics, 2014) when their daughters might be giving birth, reinforcing the point that more cohort members may become grandparents in the next few years.

Around one-in-ten respondents had one grandchild alive, and this proportion decreased as the number of grandchildren increased; however, almost 10 per cent of men and 14 per cent of women had four or more grandchildren alive. Men were more likely to have one or two parents/parents-in-law alive, whereas women were more likely to have only one member of the older generation alive. 


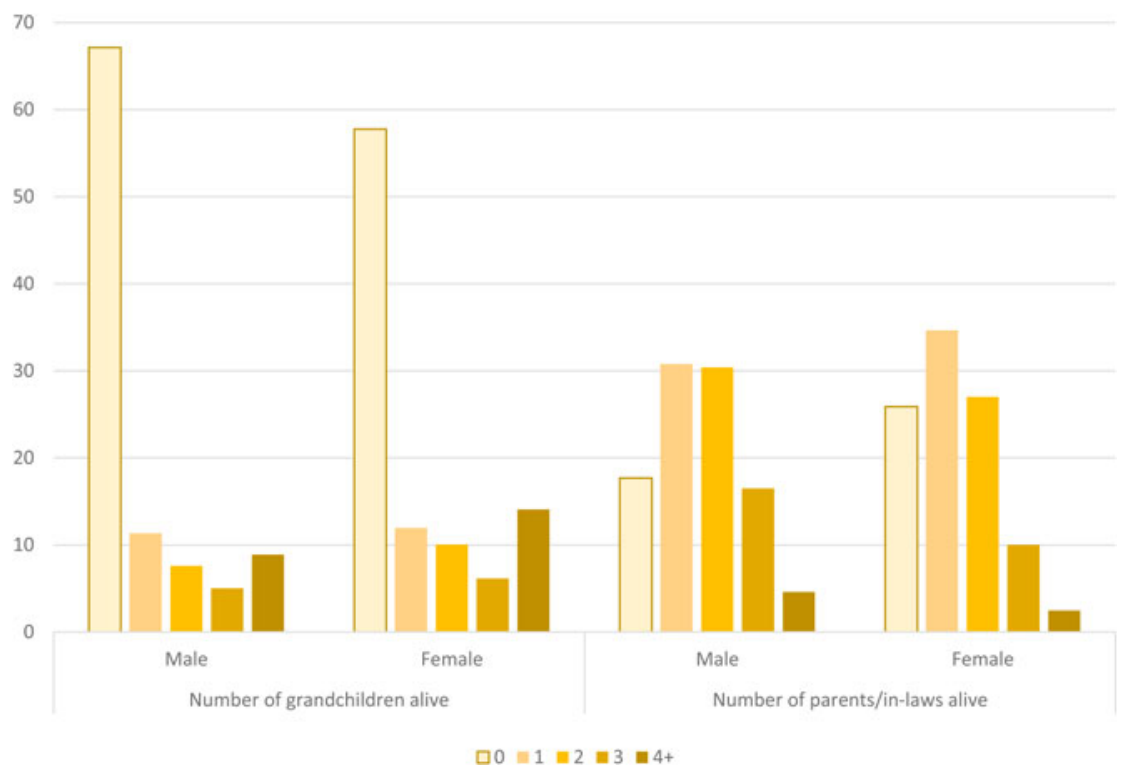

Figure 1. Percentage of cohort men $(N=1,102)$ and women $(N=1,325)$ aged 55 with at least one parent/ parent-in-law and a grandchild alive by number of grandchildren and parents/parents-in-law alive. Source: Authors' own analysis, National Child Development Study (Wave 9).

Around 30 per cent of respondents had two parents/parents-in-law alive, while 16 per cent of men and 10 per cent of women had three parents/parents-in-law alive.

\section{Exploring the characteristics of sandwich individuals}

Table 2 shows the demographic, health and socio-economic characteristics of the full sample, distinguishing by sex and whether the respondent is at risk of being 'sandwiched', using the same typology as Table 1. For example, sandwiched individuals (Group 4) are more likely to be married/in a civil partnership or co-habiting than others ( $92 \%$ of men and $86 \%$ of women). Table 1 in the online supplementary material drills deeper into the distribution of the covariates by whether those with at least one parent/parent-in-law and one grandchild alive provide help to one or both generations.

The next section focuses on respondents at risk of being a carer for multiple generations in order to investigate how their care provision is allocated between different generations. In interpreting the results, it is important to bear in mind that the analytical sample is a select group, and their characteristics vary from others in their birth cohort (see Table 1 in the online supplementary material).

\section{Provision of dual support by 'sandwich' individuals}

Table 3 outlines the combination of support towards the two generations. The table illustrates support patterns with all possible combinations in terms of the intensity of the support provided (not caring, nine hours or less per week, 10-19 hours per 
Table 2. Cohort respondents' characteristics by typology of surviving generations

\begin{tabular}{|c|c|c|c|c|c|c|c|c|c|}
\hline & \multicolumn{2}{|c|}{$\begin{array}{l}\text { Group 1: No parents } \\
\text { or grandchildren alive }\end{array}$} & \multicolumn{2}{|c|}{$\begin{array}{l}\text { Group 2: Parents, } \\
\text { no grandchild }\end{array}$} & \multicolumn{3}{|c|}{$\begin{array}{l}\text { Group 3: } \\
\text { Grandchildren } \\
\text { no parents }\end{array}$} & \multicolumn{2}{|c|}{$\begin{array}{l}\text { Group 4: Sandwiched } \\
\text { between parents and } \\
\text { grandchildren }\end{array}$} \\
\hline & Male & Female & Male & Female & Male & Female & & Male & Female \\
\hline & \multicolumn{9}{|c|}{ Percentages } \\
\hline \multicolumn{10}{|l|}{ Marital status: } \\
\hline Single/divorced/separated/widowed & 43.8 & 43.3 & 14.5 & 18.4 & 28.0 & 26.9 & & 7.9 & 14.4 \\
\hline Married/civil partner/co-habiting & 56.2 & 56.7 & 85.5 & 81.6 & 72.0 & 73.1 & & 92.1 & 85.7 \\
\hline \multicolumn{10}{|l|}{$\begin{array}{l}\text { Long-standing illness reducing ability } \\
\text { to carry out day-to-day activities: }\end{array}$} \\
\hline No illness & 60.8 & 68.1 & 71.3 & 69.8 & 64.6 & 56.6 & & 71.3 & 64.7 \\
\hline Yes, severely reduced & 10.4 & 5.1 & 4.2 & 5.0 & 11.5 & 14.2 & & 5.3 & 10.2 \\
\hline Yes, a little reduced & 14.8 & 13.6 & 10.2 & 12.2 & 13.6 & 17.3 & & 11.3 & 13.4 \\
\hline Not reduced at all & 14.1 & 13.2 & 14.3 & 13.0 & 10.3 & 12.0 & & 12.1 & 11.8 \\
\hline \multicolumn{10}{|l|}{ Perceived health: } \\
\hline Excellent/very good/good & 73.3 & 80.7 & 84.5 & 84.3 & 70.4 & 70.7 & ns & 80.6 & 75.3 \\
\hline Fair & 16.9 & 14.9 & 12.0 & 11.8 & 20.2 & 17.8 & & 13.8 & 15.7 \\
\hline Poor & 9.8 & 4.4 & 3.6 & 3.8 & 9.5 & 11.4 & & 5.6 & 9.0 \\
\hline \multicolumn{10}{|l|}{ Emotional issues: } \\
\hline No & 82.2 & 82.3 & 90.3 & 85.9 & 86.4 & 75.4 & & 90.4 & 79.8 \\
\hline Yes & 17.8 & 17.7 & 9.8 & 14.1 & 13.6 & 24.6 & & 9.6 & 20.2 \\
\hline
\end{tabular}




\begin{tabular}{|c|c|c|c|c|c|c|c|c|}
\hline \multicolumn{9}{|l|}{ Employment status: } \\
\hline Full-time job & 69.8 & 48.2 & 79.6 & 45.9 & 74.5 & 44.0 & 82.5 & 44.5 \\
\hline Part-time job & 7.9 & 31.9 & 8.3 & 34.4 & 5.4 & 27.9 & 5.4 & 29.9 \\
\hline Not working & 12.3 & 9.3 & 7.7 & 6.8 & 4.9 & 5.4 & 6.4 & 6.7 \\
\hline Looking after the home/family & 1.5 & 7.1 & 1.6 & 9.6 & 2.1 & 12.4 & 1.2 & 12.5 \\
\hline Permanently sick/disabled & 8.4 & 3.4 & 2.8 & 3.4 & 13.2 & 10.3 & 4.5 & 6.5 \\
\hline \multicolumn{9}{|l|}{ Employment status of the partner: } \\
\hline Full-time job (30+ hours) & 39.2 & 63.8 & 46.9 & 72.4 & 38.9 & 58.1 & 43.7 & 71.5 \\
\hline Part-time job ( $\leq 29$ hours) & 36.1 & 9.0 & 32.5 & 9.0 & 34.9 & 7.7 & 29.4 & 8.6 \\
\hline Not working & 12.2 & 24.0 & 7.8 & 15.1 & 6.3 & 24.7 & 8.8 & 13.9 \\
\hline Looking after home/family & 7.8 & 0.6 & 10.5 & 1.4 & 10.3 & 0.5 & 12.7 & 1.1 \\
\hline Permanently sick/disabled & 4.7 & 2.7 & 2.4 & 2.1 & 9.7 & 9.0 & 5.5 & 4.9 \\
\hline \multicolumn{9}{|l|}{ Education: } \\
\hline None & 20.5 & 10.4 & 12.6 & 8.6 & 32.9 & 25.8 & 24.1 & 19.6 \\
\hline Low O-level & 13.9 & 12.4 & 12.5 & 8.8 & 21.0 & 16.9 & 21.3 & 18.6 \\
\hline High O-level & 32.4 & 33.5 & 30.5 & 34.8 & 29.6 & 36.8 & 35.5 & 41.6 \\
\hline A-level and sub-degree & 14.5 & 17.2 & 14.6 & 17.4 & 9.5 & 9.7 & 7.9 & 10.3 \\
\hline Degree and higher & 18.7 & 26.7 & 29.8 & 30.5 & 7.0 & 10.9 & 11.3 & 9.9 \\
\hline \multicolumn{9}{|l|}{ Housing tenure: } \\
\hline Own outright & 62.3 & 68.4 & 68.1 & 68.5 & 53.9 & 56.2 & 61.6 & 61.3 \\
\hline Own with mortgage & 15.2 & 19.0 & 22.4 & 22.5 & 21.0 & 16.7 & 24.5 & 21.5 \\
\hline Rent & 20.0 & 11.5 & 7.5 & 7.1 & 23.1 & 25.6 & 11.9 & 15.9 \\
\hline Other & 2.4 & 1.0 & 2.0 & 1.9 & 2.1 & 1.6 & 2.0 & 1.3 \\
\hline
\end{tabular}


Table 2. (Continued.)

\begin{tabular}{|c|c|c|c|c|c|c|c|c|}
\hline & \multicolumn{2}{|c|}{$\begin{array}{l}\text { Group 1: No parents } \\
\text { or grandchildren alive }\end{array}$} & \multicolumn{2}{|c|}{$\begin{array}{l}\text { Group 2: Parents, } \\
\text { no grandchild }\end{array}$} & \multicolumn{2}{|c|}{$\begin{array}{l}\text { Group 3: } \\
\text { Grandchildren } \\
\text { no parents }\end{array}$} & \multicolumn{2}{|c|}{$\begin{array}{l}\text { Group 4: Sandwiched } \\
\text { between parents and } \\
\text { grandchildren }\end{array}$} \\
\hline & Male & Female & Male & Female & Male & Female & Male & Female \\
\hline \multicolumn{9}{|c|}{ Co-residence with grandchild(ren): } \\
\hline No & & & & & 95.1 & 96.3 & 95.7 & 95.8 \\
\hline Yes & & & & & 4.9 & 3.7 & 4.3 & 4.2 \\
\hline \multicolumn{9}{|c|}{ Co-residence with parents/parents-in-law: } \\
\hline No & & & 95.3 & 96.0 & & & 96.6 & 98.5 \\
\hline Yes & & & 4.7 & 4.0 & & & 3.4 & 1.5 \\
\hline $\mathrm{N}$ & \multicolumn{2}{|c|}{1,043} & \multicolumn{2}{|c|}{4,199} & \multicolumn{2}{|c|}{759} & \multicolumn{2}{|c|}{2,427} \\
\hline
\end{tabular}

Source: Authors' own analysis, National Child Development Study (Wave 9).

Significance level: ns: not significant. 
Table 3. Percentage of cohort respondents ${ }^{1}$ aged 55 by sex, hours per week of caring for grandchildren and/or parents or parents-in-law

\begin{tabular}{|c|c|c|c|c|c|c|}
\hline \multirow[b]{2}{*}{ Caring for grandchildren } & \multicolumn{4}{|c|}{ Caring for parents or parents-in-law } & \multirow[b]{2}{*}{ Total } & \multirow[b]{2}{*}{$\mathrm{N}$} \\
\hline & $\begin{array}{c}\text { Not } \\
\text { caring }\end{array}$ & $\begin{array}{c}9 \text { or less } \\
\text { hours per } \\
\text { week }\end{array}$ & $\begin{array}{l}\text { 10-19 hours } \\
\text { per week }\end{array}$ & $\begin{array}{l}20+\text { hours } \\
\text { per week }\end{array}$ & & \\
\hline \multicolumn{7}{|c|}{ Percentages } \\
\hline \multicolumn{7}{|l|}{ Men:* } \\
\hline Not caring & 12.9 & 14.2 & 1.0 & 0.6 & 28.7 & 316 \\
\hline 9 or less hours per week ${ }^{2}$ & 15.3 & 29.7 & 2.5 & 1.1 & 48.6 & 535 \\
\hline 10-19 hours per week & 3.6 & 5.9 & 1.2 & 0.7 & 11.4 & 126 \\
\hline $20+$ hours per week & 3.7 & 5.9 & 1.0 & 0.7 & 11.3 & 125 \\
\hline Total & 35.5 & 55.6 & 5.7 & 3.2 & 100.0 & \\
\hline $\mathrm{N}$ & 391 & 613 & 63 & 35 & & 1,102 \\
\hline \multicolumn{7}{|l|}{ Women: } \\
\hline Not caring & 10.0 & 8.1 & 0.8 & 0.4 & 19.3 & 255 \\
\hline 9 or less hours per week ${ }^{2}$ & 20.7 & 24.0 & 3.3 & 2.3 & 50.2 & 665 \\
\hline 10-19 hours per week & 4.5 & 6.9 & 1.4 & 1.1 & 13.8 & 182 \\
\hline $20+$ hours per week & 4.8 & 7.6 & 2.9 & 1.6 & 16.8 & 222 \\
\hline Total & 39.9 & 46.5 & 8.3 & 5.3 & 100.0 & \\
\hline $\mathrm{N}$ & 528 & 616 & 110 & 70 & & 1,324 \\
\hline
\end{tabular}

Notes: 1 . With at least one parent/parent-in-law and one grandchild alive. 2. Includes less often than once a month. Source: Authors' own analysis, National Child Development Study (Wave 9).

Significance level: * $p<0.01$.

week, 20+ hours per week). Among those 'at risk' of dual caring responsibilities, only a minority are not providing any care to either generation (13\% of men and $10 \%$ of women), and around half care for both generations. Overall, the proportion of sandwich individuals caring for both generations (50\%) is higher compared to previous UK research, using data on women aged 55-69 from the 1990s (Grundy and Henretta, 2006) and research in the USA with more recent data on men and women aged 35-75 (Friedman et al., 2015); both of which found a prevalence of around 30 per cent. This could reflect the select nature of our sample, which focuses on a single birth cohort at age 55; as many of the respondents' grandchildren are likely to be below the compulsory school age, while their older relatives might not yet need care.

Consistent with previous studies, women are more likely to provide care than men, and the provision of care is of a higher intensity towards the younger compared to the older generation (Wiemers and Bianchi, 2015). Over 71 per cent of men and 79 per cent of women provide some grandchild care whereas 65 and 60 per cent of male and female respondents, respectively, provide some support towards their parents/parents-in-law (Table 3). The intensity of the support is 
greater when caring for grandchildren, with 17 per cent of women and 11 per cent of men providing such care for more than 20 hours per week; whereas only 5 and 3 per cent of women and men, respectively, are caring for 20 hours or more per week for their parents/parents-in-law. Men in a multiple support role provide less-intense caring than women, with 30 per cent providing nine hours or less per week towards each of the two generations, compared to 24 per cent of women in the same category.

\section{Competing demands from younger and older generations}

Relatively little is known about how support towards one generation is associated with support towards another generation (Fingerman et al., 2010). This section examines whether caring for one generation increases or decreases the likelihood of caring for the other, controlling for other factors.

The results of two separate models are presented in Table 4: Model A - the odds of caring for grandchildren, controlling for the care intensity to parents/parents-inlaw; and Model B - the odds of caring for parents/parents-in-law, controlling for the care intensity to grandchildren. The top panel of the table provides strong support for the solidarity hypothesis (see Fingerman et al., 2010) in that caring for grandchildren is positively associated with caring for one's parents/parents-in-law, and vice versa. Moreover, the higher the intensity of care towards one generation, the higher the likelihood of caring for the other generation. Compared to noncarers, the provision of ten hours or more of care per week to one's parents/ parents-in-law more than trebles their chances of caring for their grandchildren, for both women (odds ratio $(O R)=3.25)$ and men $(O R=3.06)$. Similarly, when women provide high-intensity care to their grandchildren, they are more than twice as likely to care for their parents/parents-in-law (for men such risk is $80 \%$ higher).

Wider family circumstances are also important for both men and women. The number of generation members may be an indicator of the potential level of competing demand (or need) from each generation. Increasing demands from one generation have been previously found to have a negative impact on providing support to the other generation, backing the hypothesis of competing demands (Henretta et al., 1997; Friedman et al., 2015). In line with previous findings, Table 4 shows a positive association between the number of individuals in each generation and providing care for the same generation. Moreover, having a higher number of parents/parents-in-law alive is negatively associated with grandchild care provision, offering some support for the competing demands hypothesis. However, the reverse was not significant; the number of individuals in the younger generation does not seem to affect care provision towards the older generation, in contrast to Grundy and Henretta (2006). This asymmetric relationship may reflect the fact that a higher number of individuals from the older generation will have a differential impact on the time available for other roles; parents/parents-in-law are likely to live in different households, making combined care more difficult, whilst having multiple grandchildren can be, in principle, easier to accommodate in terms of care.

In terms of co-residence with the person cared for, mid-life men are more likely to care for either generation if they co-reside with them, but less likely to care for 


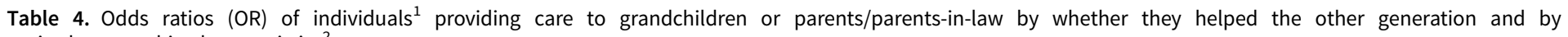
socio-demographic characteristics ${ }^{2}$

\begin{tabular}{|c|c|c|c|c|c|c|c|c|}
\hline & \multicolumn{4}{|c|}{ Model A: Grandchildren } & \multicolumn{4}{|c|}{ Model B: Parents/parents-in-law } \\
\hline & \multicolumn{2}{|c|}{ Men } & \multicolumn{2}{|c|}{ Women } & \multicolumn{2}{|c|}{ Men } & \multicolumn{2}{|c|}{ Women } \\
\hline & OR & $p$ & OR & $p$ & OR & $p$ & OR & $p$ \\
\hline \multicolumn{9}{|l|}{ Caring intensity: } \\
\hline \multicolumn{9}{|c|}{$\begin{array}{l}\text { Caring (hours per week) for parents/parents-in-law or grandchildren } \\
\text { (Ref. Not caring): }\end{array}$} \\
\hline 9 or less & 1.63 & $\star \star \star *$ & 1.57 & $\star \star \star *$ & 1.76 & 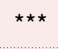 & 1.52 & ** \\
\hline $10+$ & 3.06 & $\star \star \star$ & 3.25 & $\star \star \star *$ & 1.82 & $\star \star \star *$ & 2.38 & *** \\
\hline \multicolumn{9}{|c|}{ Family circumstances (structure and proximity): } \\
\hline \multicolumn{9}{|l|}{ Number of grandchildren (Ref. 1): } \\
\hline 2 & 1.42 & * & 1.42 & * & 1.24 & & 0.96 & \\
\hline 3 & 1.23 & & 1.74 & $\star \star$ & 1.18 & & 0.91 & \\
\hline $4+$ & 1.45 & * & 1.96 & $\star \star \star$ & 1.16 & & 1.10 & \\
\hline \multicolumn{9}{|c|}{ Number of parents/in-laws (Ref. 1 ): } \\
\hline 2 & 0.89 & & 0.66 & $\star \star$ & 1.17 & & 1.32 & $\star \star$ \\
\hline 3 & 0.77 & & 0.81 & & 1.98 & 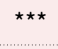 & 1.99 & 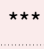 \\
\hline 4 & 0.46 & $\star \star$ & 0.41 & $\star \star$ & 1.63 & & 1.95 & * \\
\hline Co-residing with grandchildren & 2.52 & ** & 1.52 & & 0.63 & & 0.79 & \\
\hline Co-residing with parents/in-laws & 0.40 & ** & 1.68 & & 2.66 & ** & 2.34 & \\
\hline
\end{tabular}


Table 4. (Continued.)

\begin{tabular}{|c|c|c|c|c|c|c|c|}
\hline & \multicolumn{4}{|c|}{ Model A: Grandchildren } & \multicolumn{3}{|c|}{ Model B: Parents/parents-in-law } \\
\hline & \multicolumn{2}{|c|}{ Men } & \multicolumn{2}{|c|}{ Women } & \multicolumn{2}{|c|}{ Men } & Women \\
\hline \multicolumn{8}{|l|}{ Partnership status: } \\
\hline \multicolumn{8}{|c|}{ Relationship (Ref. Single/divorced/separated/widowed): } \\
\hline Constant & 0.47 & & 2.25 & & 0.61 & & 0.68 \\
\hline $\mathrm{N}$ & 1,098 & & 1,315 & & 1,098 & & 1,315 \\
\hline
\end{tabular}

Notes: 1. Individuals with at least one parent/parent-in-law and one grandchild alive. 2. Full model in Table 2 in the online supplementary material. Additional covariates included in both models: health indicators (long-standing illness, emotional issues, perceived health); socio-economic resources (own employment, partner's employment, education level, housing tenure). Ref.: reference category.

Source: Authors' own analysis, National Child Development Study (Wave 9).

Significance levels: ${ }^{\star} p<0.10,{ }^{\star \star} p<0.05,{ }^{\star \star \star} p<0.01$. 
one generation if they are living with the other generation. By contrast, co-residence with either generation is not associated with women's likelihood of caring. Specific individual characteristics mediate the likelihood of caring for either generation. Sandwiched individuals in a relationship are more likely to care for grandchildren than those not in a relationship, however, the same is not observed in terms of caring for one's parents/parents-in-law. Finally, socio-economic characteristics have a complex impact on caring, e.g. permanently sick/disabled women are less likely than those working full-time to care for grandchildren and those in part-time jobs are more likely to support their parents/parents-in-law; while men who rent their accommodation are less likely to care for grandchildren compared to those who own their home outright (see Table 2 in the online supplementary material).

\section{Characteristics of sandwich care-givers towards multiple generations}

Table 5 (men) and Table 6 (women) present the results of multinomial regression models of the probabilities of caring for grandchildren only, parent/parents-in-law only, or neither generation, in comparison with caring for both generations (the omitted category). Both men and women are more likely to provide care for both generations than to care only for parents/parents-in-law, if they are in a partnership. The structure of the family is significant, in line with the findings in the previous section. For both women and men, having more grandchildren is associated with higher odds of being a dual carer compared to not caring for either generation. Interestingly, having more parents/parents-in-law is associated with a lower risk of caring only for grandchildren relative to being a dual carer, for both men and women. However, a higher number of parents/parents-in-law is also associated with higher odds of caring only for parents/parents-in-law (relative risk ratio $(\mathrm{RRR})=2.39$ for men and $\mathrm{RRR}=2.67$ for women, with four parents/parents-in-law alive) compared with caring for both generations, offering some evidence for the competing needs hypothesis; residing with parents/parents-in-law makes one more likely to be caring for both generations only for men.

Additional analysis shown in Tables 3 and 4 in the online supplementary material highlights the complex impact of health and socio-economic characteristics: women with a long-standing illness which does not severely reduce their daily activities are more likely to care for both generations than only for their parents/ parents-in-law. For men, those with excellent/very good/good or fair health are more likely to be dual care-givers compared to caring only for grandchildren. Interestingly, men's own employment status is not significant, although those men whose partner has a part-time job were less likely to care for neither generation than for both, again supporting the notion that men may provide care as part of a couple. For women, their partner's employment was not significant. Women 'looking after home/family' were less likely to care only for their parents $(\mathrm{RRR}=0.51)$ or grandchildren $(\mathrm{RRR}=0.54)$ than for both generations, whereas permanently sick or disabled women were four times more likely to care for neither generation than for both (RRR = 4.39). In general, men and women with higher qualifications were more likely to care for one generation than for both. In contrast, those renting as opposed to being owner-occupiers were more likely to care for neither generation than for both. 
Table 5. Multinomial models: relative risk ratios (RRR) of men $^{1}$ aged 55 years of helping only grandchildren, only parents/parents-in-law or neither generation relative to caring for both generations ${ }^{2,3}$

\begin{tabular}{|c|c|c|c|c|c|c|}
\hline \multirow{2}{*}{$\begin{array}{l}\text { Base outcome } \\
\text { (caring for both generations) }\end{array}$} & \multicolumn{2}{|c|}{$\begin{array}{c}\text { Only } \\
\text { grandchildren }\end{array}$} & \multicolumn{2}{|c|}{$\begin{array}{l}\text { Only parents/ } \\
\text { in-laws }\end{array}$} & \multicolumn{2}{|c|}{ None } \\
\hline & RRR & $p$ & RRR & $p$ & RRR & $p$ \\
\hline \multicolumn{7}{|l|}{ Partnership status: } \\
\hline \multicolumn{7}{|l|}{$\begin{array}{l}\text { Relationship (Ref. Single/ } \\
\text { divorced/separated/widowed): }\end{array}$} \\
\hline $\begin{array}{l}\text { Married/civil partner/ } \\
\text { co-habiting }\end{array}$ & 0.82 & & 0.17 & $\star \star \star \star$ & 0.41 & $\star \star$ \\
\hline \multicolumn{7}{|l|}{$\begin{array}{l}\text { Family circumstances } \\
\text { (structure and proximity): }\end{array}$} \\
\hline \multicolumn{7}{|l|}{$\begin{array}{l}\text { Number of grandchildren } \\
\text { (Ref. 1): }\end{array}$} \\
\hline 2 & 0.85 & & 0.75 & & 0.53 & ** \\
\hline 3 & 0.99 & & 0.96 & & 0.55 & * \\
\hline $4+$ & 0.91 & & 0.71 & & 0.58 & ** \\
\hline \multicolumn{7}{|l|}{$\begin{array}{l}\text { Number of parents/ } \\
\text { in-laws (Ref. 1): }\end{array}$} \\
\hline 2 & 0.94 & & 1.28 & & 0.88 & \\
\hline 3 & 0.59 & $\star \star$ & 1.58 & * & 0.57 & * \\
\hline 4 & 0.63 & & 2.39 & $\star \star$ & 1.33 & \\
\hline Co-residing with grandchildren & 1.49 & & 0.36 & & 0.66 & \\
\hline $\begin{array}{l}\text { Co-residing with parents/ } \\
\text { in-laws }\end{array}$ & 0.07 & $\star \star$ & 1.27 & & 0.91 & \\
\hline Constant & 2.13 & & 2.28 & & 2.09 & \\
\hline
\end{tabular}

Notes: $\mathrm{N}=1$ 1,098. 1. Individuals with at least one parent/parent-in-law and one grandchild alive. 2. Day-to-day activities include washing and dressing, household cleaning, cooking, shopping for essentials, using public/private transport, walking a defined distance, climbing stairs, remembering to pay bills, lifting objects from ground/work surface, gardening, gripping objects; hearing and speaking in a noisy room. 3 . Full model in Table 3 in the online supplementary material. Additional covariates included in all models: health indicators (long-standing illness, emotional issues, perceived health); socio-economic resources (own employment, partner's employment, education level, housing tenure). Ref.: reference category.

Source: Authors' own analysis, National Child Development Study (Wave 9).

Significance levels: ${ }^{\star} p<0.10,{ }^{\star \star} p<0.05,{ }^{\star \star \star} p<0.01$.

\section{Discussion and implications}

This paper investigates the characteristics and care-giving allocation of 'sandwich individuals' using a nationally representative data-set for Britain. Consistent with previous studies, the findings show that one-third of individuals aged 55 find themselves 'caught in the middle' or 'sandwiched' between their surviving parents/ parents-in-law and their grandchildren (Wiemers and Bianchi, 2015). However, once 'at risk', the level of care provision by mid-life individuals is higher than previously found (Evandrou and Glaser, 2004; Grundy and Henretta, 2006), with 
Table 6. Multinomial models: relative risk ratios (RRR) of women ${ }^{1}$ aged 55 years of helping only grandchildren, only parents/parents-in-law or neither generation relative to caring for both generations $s^{2,3}$

\begin{tabular}{|c|c|c|c|c|c|c|}
\hline \multirow{2}{*}{$\begin{array}{l}\text { Base outcome } \\
\text { (caring for both generations) }\end{array}$} & \multicolumn{2}{|c|}{$\begin{array}{c}\text { Only } \\
\text { grandchildren }\end{array}$} & \multicolumn{2}{|c|}{$\begin{array}{l}\text { Only parents/ } \\
\text { in-laws }\end{array}$} & \multicolumn{2}{|c|}{ None } \\
\hline & RRR & $p$ & RRR & $p$ & RRR & $p$ \\
\hline \multicolumn{7}{|l|}{ Partnership status: } \\
\hline $\begin{array}{l}\text { Relationship (Ref. Single/ } \\
\text { divorced/separated/widowed): }\end{array}$ & 1.11 & & 0.59 & * & 0.64 & \\
\hline \multicolumn{7}{|l|}{$\begin{array}{l}\text { Married/civil partner/ } \\
\text { co-habiting }\end{array}$} \\
\hline \multicolumn{7}{|l|}{$\begin{array}{l}\text { Family circumstances (structure } \\
\text { and proximity): }\end{array}$} \\
\hline \multicolumn{7}{|l|}{$\begin{array}{l}\text { Number of grandchildren } \\
\text { (Ref. 1): }\end{array}$} \\
\hline 2 & 1.01 & & 0.68 & & 0.74 & \\
\hline 3 & 1.11 & & 0.60 & & 0.62 & \\
\hline $4+$ & 0.91 & & 0.51 & ** & 0.44 & $\star \star * *$ \\
\hline \multicolumn{7}{|l|}{$\begin{array}{l}\text { Number of parents/in-laws } \\
\text { (Ref. 1): }\end{array}$} \\
\hline 2 & 0.76 & * & 1.60 & ** & 1.13 & \\
\hline 3 & 0.48 & 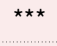 & 1.18 & & 0.66 & \\
\hline 4 & 0.52 & * & 2.67 & ** & 1.06 & \\
\hline Co-residing with grandchildren & 1.05 & & 0.49 & & 0.89 & \\
\hline Co-residing with parents/in-laws & 0.53 & & 0.70 & & - & \\
\hline Constant & 0.89 & & 0.26 & & 0.37 & \\
\hline
\end{tabular}

Notes: $\mathrm{N}=1,315.1$. Individuals with at least one parent/parent-in-law and one grandchild alive. 2 . Day-to-day activities include washing and dressing, household cleaning, cooking, shopping for essentials, using public/private transport, walking a defined distance, climbing stairs, remembering to pay bills, lifting objects from ground/work surface, gardening, gripping objects; hearing and speaking in a noisy room. 3. Full model in Table 4 in the online supplementary material. Additional covariates included in all models: health indicators (long-standing illness, emotional issues, perceived health); socio-economic resources (own employment, partner's employment, education level, housing tenure). Ref.: reference category.

Source: Authors' own analysis, National Child Development Study (Wave 9).

Significance levels: ${ }^{\star} p<0.10,{ }^{\star \star} p<0.05,{ }^{\star \star \star} p<0.01$.

around half providing care for more than one generation simultaneously. Indeed, this may be an underestimate as we only account for the provision of grandchild care in terms of downwards support, excluding other ongoing support to adult children (Heath and Calvert, 2013).

The key objective of the paper has been to examine whether caring for one generation competes with the provision of caring for another among so-called 'sandwiched' individuals. If this were the case, we would expect a 'rationalisation' of care provision, with care provided to one generation being associated with a reduced likelihood of caring for the other. The alternative perspective is that family members provide care regardless of how high the care demand is, and thus care for 
one generation is positively associated with care for the other. These results offer support to this 'family solidarity' hypothesis as caring for grandchildren increases the probability of also caring for parents/parents-in-law, and vice versa. Such results have been found in previous research (Grundy and Henretta, 2006; Lumsdaine and Vermeer, 2015). An extension of previous work was also to control for the intensity of the care provided, and we found that the higher the intensity of caring for one generation, the higher the chances of caring for the other generation, with stronger effects of the intensity of elder care on the provision of grandchild care, for both women and men.

However, we also found evidence that where 'need' or demands are higher, competition for scarce time resources may squeeze out support for the other generation. The results are asymmetric, with no evidence that more grandchildren result in a lower likelihood of caring for one's parents, nevertheless having three or more surviving parents/parents-in-law does adversely affect the likelihood of caring for grandchildren. Our results also suggest that women who were working part-time or not at all were more likely to be dual care-givers, suggesting that women may find it more difficult to combine paid work with multiple care-giving than with caring for only one generation. Caring responsibilities for older parents affect the employment of mid-life individuals (Gomez-Leon et al., 2019) and may also have an indirect effect on their adult children's employment through limiting the provision of grandchild care (Dykstra and Fokkema, 2011).

As improvements in survivorship continue, more people will find themselves living longer with multiple generations. Importantly, over half of the birth cohort studied here (born in 1958) had parents/parents-in-law alive but were yet to become grandparents. This suggests that over the coming decade more of this cohort will find themselves juggling family obligations across multiple generations. This research will be extended by analysing the data (yet to be available) when the study cohort is aged 60 years old. Such data will be important to inform the design of social policy across a range of areas, including support for carers and working parents, informing the feasibility of achieving 'fuller working lives' (Department for Work and Pensions, 2017). There may be trade-offs between encouraging people to remain in work longer, continued reliance on families for the provision of long-term care and a greater role for grandparents in caring for their grandchildren.

Author ORCIDs. (D) Athina Vlachantoni, 0000-0003-1539-3057

Supplementary material. The supplementary material for this article can be found at https://doi.org/10. 1017/S0144686X19000047.

Funding. This work was supported by the Economic and Social Research Council (ESRC) Centre for Population Change (grant number ES/K007394/1) at the University of Southampton.

\section{References}

Abramson TA (2015) Older adults: the 'panini sandwich' generation. Clinical Gerontologist 38, 251-267. Agree E, Bissett B and Rendall MS (2003) Simultaneous care for parents and care for children among mid-life British women and men. Population Trends 112, 29-35.

Arpino B and Bordone V (2017) Regular provision of grandchild care and participation in social activities. Review of Economics of the Household 15, 135-174. 
Dahlberg L, Demack S and Bambra C (2007) Age and gender of informal carers: a population-based study in the UK. Health and Social Care in the Community 15, 439-445.

Department for Education (2014) Childcare and Early Education: Millions of Parents to Get Help with Childcare Costs. Available at https:/www.gov.uk/government/news/millions-of-parents-to-get-helpwith-childcare-costs.

Department for Work and Pensions (2017) Fuller Working Lives: A Partnership Approach. London: Department for Work and Pensions.

Dykstra PA and Fokkema T (2011) Relationships between parents and their adult children: a West European typology of late-life families. Ageing \& Society 31, 545-569.

Evandrou M, Falkingham J, Gomez-Leon M and Vlachantoni A (2018) Intergenerational flows of support between parents and adult children in Britain. Ageing \& Society 38, 321-351.

Evandrou M and Glaser K (2002) Changing economic and social roles: the experience of four cohorts of mid-life individuals in Britain, 1985-2000. Population Trends 110, 19-30.

Evandrou M and Glaser K (2004) Family, work and quality of life: changing economic and social roles through the lifecourse. Ageing \& Society 24, 771-791.

Evandrou M, Glaser K and Henz U (2002) Multiple role occupancy in midlife: balancing work and family life in Britain. The Gerontologist 42, 781-789.

Fingerman KL, Pillemer KA, Silverstein M and Suitor JJ (2012) The baby boomers' intergenerational relationships. The Gerontologist 52, 199-209.

Fingerman KL, Pitzer LM, Chan W, Birditt K, Franks MM and Zarit S (2010) Who gets what and why? Help middle-aged adults provide to parents and grown children. Journals of Gerontology: Psychological Sciences and Social Sciences 66B, 87-98.

Friedman EM, Park SS and Wiemers EE (2015) New estimates of the sandwich generation in the 2013 panel study of income dynamics. The Gerontologist 57, 191-196.

Glaser K, Evandrou M and Tomassini C (2006) Multiple role occupancy and social participation among midlife wives and husbands in the United Kingdom. International Journal of Aging and Human Development 63, 27-47.

Gomez-Leon M, Evandrou M, Falkingham J and Vlachantoni A (2019) The dynamics of social care and employment in mid-life. Ageing \& Society 39, 381-408.

Grundy E and Henretta JC (2006) Between elderly parents and adult children: a new look at the intergenerational care provided by the 'sandwich generation'. Ageing \& Society 26, 707-722.

Heath S and Calvert E (2013) Gifts, loans and intergenerational support for young adults. Sociology 47, $1120-1135$.

Henretta JC, Hill MS, Li W, Soldo BJ and Wolf DA (1997) Selection of children to provide care: the effect of earlier parental transfers. Journals of Gerontology: Psychological Sciences and Social Sciences 52B, 110-119.

Lumsdaine RL and Vermeer SJC (2015) Retirement timing of women and the role of care responsibilities for grandchildren. Demography 52, 433-454.

McGarrigle C and Kenny RA (2013) Profile of the Sandwich Generation and Intergenerational Transfers in Ireland. Dublin: The Irish Longitudinal Study on Ageing.

Miller DA (1981) The 'sandwich' generation: adult children of the aging. Social Work 26, 419-423.

Murphy M and Grundy E (2003) Mothers with living children and children with living mothers: the role of fertility and mortality in the period 1911-2050. Population Trends 112, 36-44.

Office for National Statistics (2014) Birth by Parents' Characteristics in England and Wales 2013. Available at https://www.ons.gov.uk/peoplepopulationandcommunity/birthsdeathsandmarriages/live births/bulletins/birthsbyparentscharacteristicsinenglandandwales/2014.

Office for National Statistics (2016) Childbearing for Women Born in Different Years, England and Wales 2016. Available at https://www.ons.gov.uk/peoplepopulationandcommunity/birthsdeathsandmarriages/ conceptionandfertilityrates/datasets/childbearingforwomenbornindifferentyearsreferencetable.

Pierett CR (2006) The 'sandwich generation': women caring for parents and children. Monthly Labour Review 129, 3-9.

Robards J, Vlachantoni A, Evandrou M and Falkingham J (2015) Informal caring in England and Wales - stability and transition between 2001 and 2011. Advances in Life Course Research 24, 21-33. 
Rogerson PA and Kim D (2005) Population distribution and redistribution of the baby-boom cohort in the United States: recent trends and implications. Proceedings of the National Academy of Sciences 102, 15319-15324.

Rosenthal CJ, Martin-Matthews A and Matthews SH (1996) Caught in the middle? Occupancy in multiple roles and help to parents in a national probability sample of Canadian adults. Journals of Gerontology: Psychological Sciences and Social Sciences 51B, S274-S283.

Rubin R and White-Means S (2009) Informal caregiving: dilemmas of sandwiched caregivers. Journal of Family and Economic Issues 30, 252-267.

Stephens M and Blenkinsopp S (2015) Young People and Social Security: An International Review. York, UK: Joseph Rowntree Foundation.

Stone J, Berrington A and Falkingham J (2014) Gender, turning points, and boomerangs: returning home in young adulthood in Great Britain. Demography 51, 257-276.

Wiemers EE and Bianchi SM (2015) Competing demands from aging parents and adult children in two cohorts of American women. Population and Development Review 41, 127-146.

Cite this article: Vlachantoni A, Evandrou M, Falkingham J, Gomez-Leon M (2020). Caught in the middle in mid-life: provision of care across multiple generations. Ageing \& Society 40, 1490-1510. https://doi.org/ $10.1017 /$ S0144686X19000047 